\title{
Individual differences in the reduction degree of the Korean suffix 'nin'
}

\author{
Jungsun Kim* \\ Graduate School of Education, Yeungnam University, Gyeongsan, Korea
}

\begin{abstract}
The present study examines the degree of suffix reduction that occurs when the Korean suffix [-nin] was attached to the root in spontaneous Seoul Korean speech. Specifically, it focuses on the degrees of reduction produced by individual speakers. The degree of reduction was assessed as the duration of the suffix [-nin] to clarify the continuum between the full and reduced forms. The results revealed that, first, the reduced forms of the suffix [-nin] were significantly distinguished from the full forms in the suffixation processes. Second, regarding parts of speech, the differences among individual speakers on the degrees of reduction were clearer when the suffix [-nin] was attached to verbs, rather than nouns and pronouns. Finally, the length of a root played a critical role in determining the degree of reduction of the suffix [-nin]. The degrees of reduction for individual speakers significantly differed when the suffix [-nin] was attached to two-syllable roots than three- and four-syllable roots. In conclusion, individual differences in the degrees of reduction were likely to occur when the roots are verbs and when two-syllable roots.
\end{abstract}

Keywords: reduction, suffix, individual differences, spontaneous speech, Seoul Korean

\section{Introduction}

Morphemes are classified into the basic categories of roots and affixes. Affixes are classified as prefixes, infixes, and suffixes. The pronunciation of each affix in spontaneous speech is varied when it is attached to the root. The present study is focused on a categorical or gradient effect, showing the relation between the full form (i.e., citation form) and reduced form of the Korean suffix, [-nin]. Examples of coda deletion in the reduced form are provided below along with their corresponding full forms for comparison.
(1) The full and reduced forms of the suffix 'nin'

\begin{tabular}{|c|c|c|}
\hline $\begin{array}{l}\text { Full form } \\
\text { [ə.mə.ni.nin] }\end{array}$ & $\begin{array}{l}\text { Reduced form } \\
\text { [ə.mə.ni.ni] }\end{array}$ & $\begin{array}{l}\text { Gloss } \\
\text { 'mother-Nom' }\end{array}$ \\
\hline nin] & [t $\left.\int \partial . n i\right]$ & 'I-Nom' \\
\hline [tfu.nin] & [tfu.ni $]$ & 'give-Nom' \\
\hline
\end{tabular}

The example in (1a) shows the deletion of the alveolar nasal [n] that is attached to the noun root [ə.mə.ni]. In (1b), [t $\int$ ə] is the pronoun, and the suffix [nin] is attached to the pronoun root. (1b) shows the suffix coda deletion of [t $\mathrm{f}$ ə.ni]. In (1c), $[\mathrm{t} f \mathrm{u}]$ is a verb root, and (1c) shows coda deletion of [ni].

\footnotetext{
*jngsnkim@gmail.com, Corresponding author

Received 29 April 2020; Revised 11 June 2020; Accepted 11 June 2020

(C) Copyright 2020 Korean Society of Speech Sciences. This is an Open-Access article distributed under the terms of the Creative Commons Attribution NonCommercial License (http://creativecommons.org/licenses/by-nc/4.0) which permits unrestricted non-commercial use, distribution, and reproduction in any medium, provided the original work is properly cited.
} 
The previous literature related to the suffixation processes as not directly concerned with morphemic reductions. Most previous studies about morphemic reductions have focused on the relation between morphological and phonological processes (Coetzee \& Pater, 2001; Guy, 1991).

Coetzee \& Pater (2011) studied morphological distributions relative to reduction processes. The comparison of words containing one morpheme [mist] 'mist' and two morphemes [mist] 'missed' reveals the preservation of the second morpheme (i.e., a past tense suffix); in other words, the deletion rates of the past tense suffix were much lower than those of the final segment of the monomorphemic word [mist] 'mist'. In this sense, the word [mist] 'missed' consists of a root, the first morpheme [mis], and a suffix, the second morpheme [t]; and the second morpheme [ $\mathrm{t}$ ] in 'missed' tends to block the deletion process in some dialects. The morphemes [mis] and $[t]$ in 'missed' have distinctive morphemic boundaries across dialects in English (e.g., Philadelphia English, Chicanon English, Tejano English). Chicano English has more distinctions between morphemes than do other dialects of English (Bayley, 1997; Guy, 1991; Santa Ana, 1992). In contrast, in the case of monomorphemic words (e.g., [mist] 'mist'), the final segment of the word often tends to be deleted (Coetzee \& Pater, 2011).

Johnson (2004) showed that the reduction process of [pra.bo.bli] 'probably' is [pra.bli] - [pra.li] - $\left[\mathrm{pra}^{\mathrm{I}}\right]$. The word 'probable' is an adjective and can be considered as one morpheme. The morpheme [li] '-ly' is a derivational suffix serving to create an adverb. In the process of this reduction form [pra.li], the second syllable [bə] is deleted, but the last syllable [li] '-ly' indicating the adverb is not changed or deleted in this morpheme structure. The form showing the most extreme reduction, $\left[\mathrm{pra}^{\mathrm{I}}\right]$, contains the first syllable of the word 'probably' and the vowel of the other morpheme '-ly'. In other words, the resistance to the reduction of [li] '-ly' is expressed as the $\left.{ }^{\mathrm{I}}\right]$ in $\left[\mathrm{a}^{\mathrm{I}}\right]$, which indicates the adverbial quality of this word. In another of Johnson's examples, when the word 'apparently' is pronounced with extreme reduction, two syllables [p $\mathrm{p}^{\mathrm{h}}$.II] appear in spoken English; 'apparent' is reduced to $\left[\mathrm{p}^{\mathrm{h}} \varepsilon\right]$, which is the second syllable of the full word, and segmental reduction is applied to the adverbial suffix '-ly' to yield [ $\mathrm{r}]$. Morphemes that give crucial information to listeners constrain the reduction processes so that there remain two distinctive morphemes $\left[\mathrm{p}^{\mathrm{h}} \varepsilon\right]$ and $[\mathrm{rt}]$ in 'apparently'.

The reduction patterns appear from the effects of various factors such as the frequency of words, the phonetic property of grammatical category, and the reduction of the number of syllables (Bock, 1995; Bybee, 2001; Cooper \& Paccia-Cooper, 1980; Ernestus, 2000; Johnson, 2004; Jurafsky et al., 2001; Levelt, 1989; Lohmann \& Conwell, 2020; Pluymaekers, 2007; Umeda, 1977). Pluymaekers (2007) investigated the durational reduction of four affixes occurring in different carrier words. This study found that the carrier word with a high frequency led to reduce its acoustic duration. Jurafsky et al. (2001) examined the 10 most frequent English function words drawn from the Switchboard corpus of telephone conversations. Their results showed that there were the effects of predictability on function word reduction which was gradient. That is, when the function word was predictable, the duration was likely to be shorter and more reduced. Lohmann \& Conwell (2020) investigated whether there were durational differences between grammatical categories (e.g., parts of speech: nouns vs. verbs). Their study was conducted as a production test to examine the difference in duration between twelve noun-verb homophone pairs in controlled sentence-medial contexts. They found evidence that nouns had the greater duration than verbs, showing the effects of prosodic boundaries and lexical frequency. Johnson (2004) studied reduction in American English from the Variation in Conversation corpus. The result of this study showed that longer words were more likely to be reduced than shorter words. That is, $30 \%$ of syllable deletion appeared from longer content words, while two syllable content words showed syllable deletion rates of $6 \%$.

The reduction processes in Korean have mostly studied segmental or syllable deletions (Hong \& Park, 2016; Kim, 2016). Hong \& Park (2016) examined the reduction of words in Korean casual speech, employing the perspective of information theory. Their study was focused on subsyllabic reduction. They proposed to improve the well-formedness related to segmental string and the mutual information between the full and reduced forms. Kim (2016) studied the reductive effect of affixes in spontaneous Seoul Korean speech. The results of this study showed that the codas of word-final affixes tended to be more deleted than in word-internal positions or in roots. Also there were the coda reductions of high-frequency affixes 'nin' and 'lil'.

When measuring articulatory reduction, there is a wide range of measurements. The previous studies (Pluymaekers, 2007; Scarborough, 2004; Shields \& Balota, 1991; Van Son \& Pols, 2003; Wright, 1997) showed various measures such as mean amplitude, spectral characteristics of gravity, centralization degrees in vowels, differences in F1 and F2, and acoustic duration. According to Pluymaekers (2007), the acoustic duration is one of the measurements that has been studied most comprehensively. The present paper studied the suffix reduction process by measuring the acoustic duration of the Korean suffix [-nin].

Considering the previous studies associated with the patterns of reduction, there has been little discussion of affix reduction in the Korean spontaneous speech. The present study explores the degrees of reduction of the Korean suffix [-nin] showing the differences of individual speakers. The present study examined the following three research questions: First, are there differences in the degrees of reduction between the full and reduced forms of the suffix [-nin]? Second, are there individual differences in the degrees of reduction when the suffix [-nin] is attached to the parts of speech (i.e., nouns, verbs, and pronouns)? Last, are there individual differences in the degrees of reduction when the suffix [-nin] is attached to the length of each root (e.g., the number of syllables)? The present study investigates the reduction degrees of the Korean suffix [-nin] with these research questions.

\section{Experimental Method}

\subsection{Subjects}

This experiment involved 10 subjects, 5 males and 5 females, in their 20s. The subjects were selected from the Spontaneous Seoul Korean Speech corpus (Yun et al., 2015). All the subjects were born and raised in the Seoul area, their hometown. They were paid for their participation in this experiment. 


\subsection{Speech material}

This dataset consisted of words collected from the Spontaneous Seoul Korean Speech corpus. The collected words are labelled in the corpus. There were 1,187 experimental words $^{1}$ including several morpheme distinctions. The collected words were divided into roots and suffixes. The study focused on suffix reduction, particularly coda deletion, which may include vowel reduction.

Figure 1 illustrates the reduction with a waveform and spectrogram showing the suffix [-nin]. In Figure (1a), the full form (a.k.a. citation form) displays the typical pronunciation of the suffix [-nin] 'nominative form' (i.e., 는: Korean alphabet) and the root, [ə.mə.ni] 'mother' (i.e., 어머니: Korean alphabet). However, in Figure (1b), the suffix [-nin] is reduced in the waveform and spectrogram. As this phonetic form is transcribed, the coda is deleted. As transcribed in (1b), there is deleted nasal coda in the suffix.

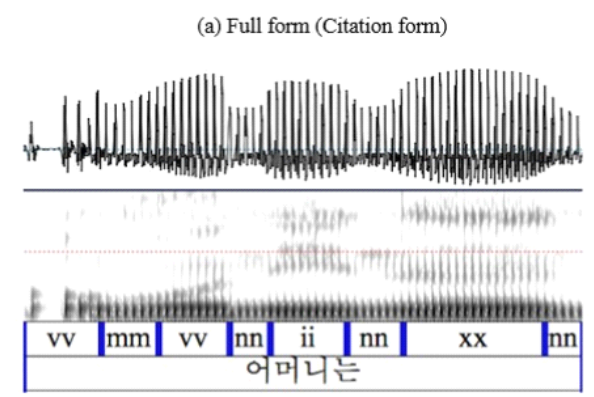

Roman Symbols

(b) Reduced form

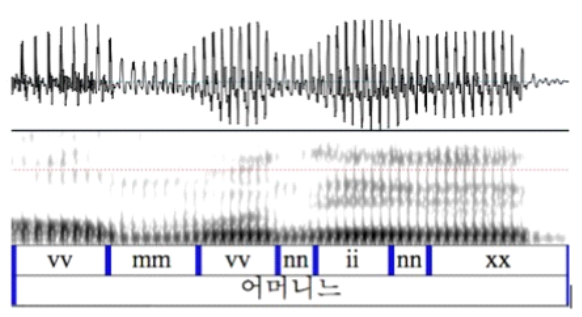

Roman Symbols
Korean Alphabet

Figure 1. The two types of morphemes in the full form (i.e., the citation form of the root and suffix) in (1a) and the reduced form (i.e., deletion of an alveolar nasal in the suffix) in (1b)

\subsection{Data analysis}

When the suffix [-nin] is added to the roots in spontaneous Seoul Korean speech, the pronunciation forms may appear as full and reduced forms. The pronunciation types were assessed by a mixed-effect linear regression model, using the lmer function in the lme4 package (Bates et al., 2015) in R software, version 3.5.1. The mean values of the full and reduced forms were tested by measuring the suffix [-nin] duration, which is the dependent variable. The fixed effects predictors are the forms of pronunciation (i.e., full and reduced forms), parts of speech (i.e., nouns, verbs, pronouns, adjectives, adverbs) and the number of syllables. The random effect for speakers describes the degree of reduction triggered by the types of pronunciation. The Markov Chain Monte Carlo (MCMC) package (Martin et al., 2011) was conducted to provide the probability value (i.e., $p$-value). The $p$-values were calculated for the specific values of individual differences on the degree of reduction.

\section{Results}

\subsection{The forms of pronunciation}

The pronunciation of the Korean suffix, [nin], when it is added to the root, does not show the constant forms from the various speeches of speakers. The present study measured the duration of the Korean suffix to examine the forms of pronunciation. The Figure 2 shows the mean values of the full form and reduced form. The reduced form as indicated in Figure 1 appears as the deletion of a coda consonant. As shown in Figure 2 , there was a significant difference between the full and reduced form $(\beta=-0.118, t=-11.71, p<.001)$. The overall range for the durations of the full forms shows between 0.0 and $1.0 \mathrm{sec}$. On the other hand, the dots for the durations of the reduced forms are converged between 0.0 and 0.5 sec., though there are a couple of outliers above the $0.5 \mathrm{sec}$. This indicates that the reduced forms tend to have the coda deletions, compared to those of the full forms.

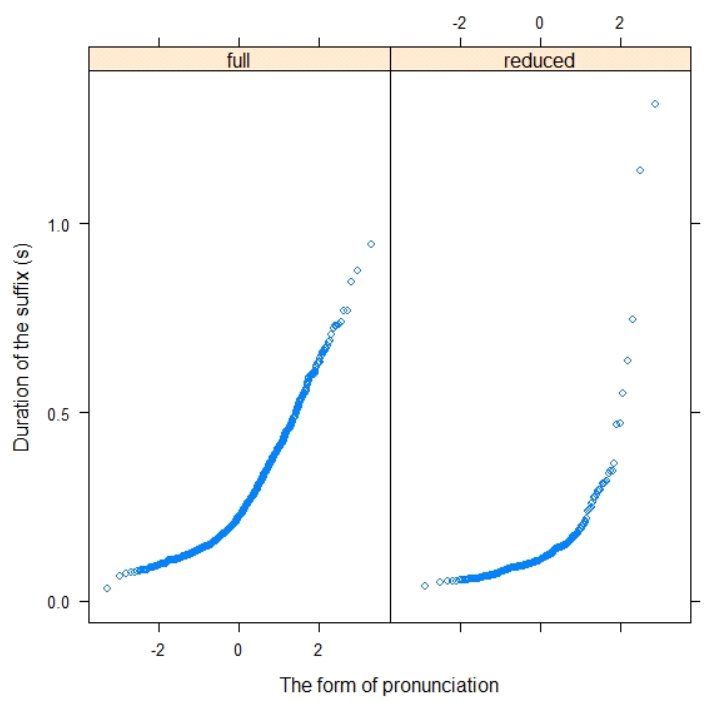

Figure 2. The forms of pronunciation for the Korean suffix [nin]

1 The numbers of the experimental words were marked by individual speakers and parts of speech. M1: nouns (75), pronouns (18), verbs (43), M2: nouns (55), pronouns (44), verbs (48), M3: nouns (81), pronouns (34), verbs (47), M4: nouns (35), pronouns (22), verbs (41), M5: nouns (31), pronouns (42), verbs (39), F1: nouns (35), pronouns (13), verbs (41), F2: nouns (42), pronouns (35), verbs (34), F3: nouns (42), pronouns (28), verbs (32), F4: nouns (43), pronouns (25), verbs (44), F5: nouns (38), pronouns (46), verbs (34). 


\subsection{The degree of reduction based on parts of speech}

When the suffix [-nin] is attached to the parts of speech (e.g., nouns, verbs, and pronouns), speakers may have various types of pronunciation. The present study distinguishes the degree of reduction under two types of pronunciation, which are full and reduced forms. Figure 3 shows the degree of reduction of individual speakers when the suffix [-nin] is attached to the nouns in spontaneous Seoul Korean speech. In the Figure 3, the curves for the degree of reduction displayed variations among speakers. Some speakers (i.e., F1, F2) showed similar curves, but other speakers showed the different degree of reduction curves. In particular, there was a distinction on the curve of the speaker, F4, which might be a categorical boundary between full and reduced form. Other speakers showed gradient curves between full and reduced forms, though there were different slopes for the degrees of reduction.

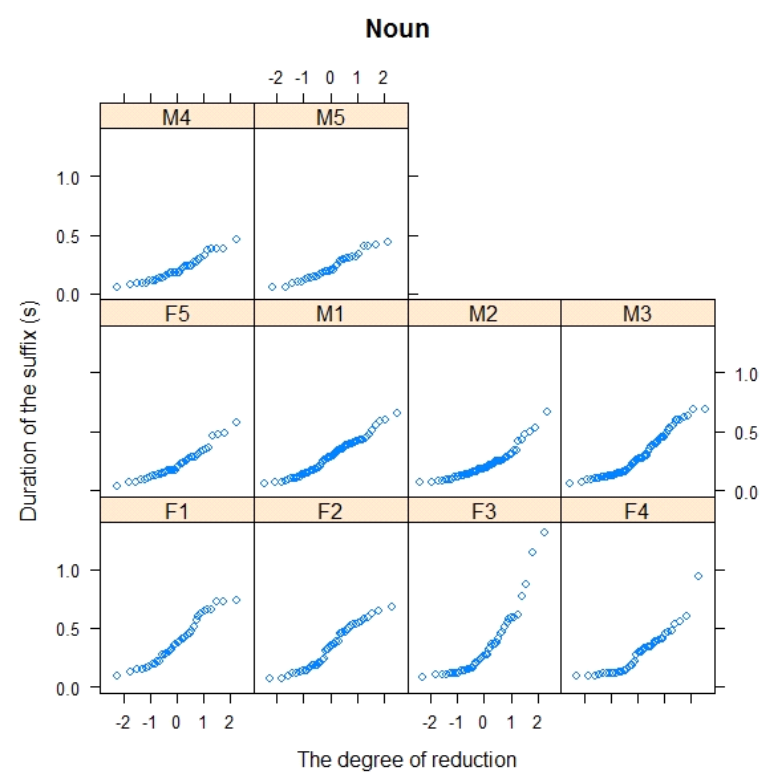

Figure 3. The degree of reduction for each speaker when the Korean suffix [-nin] is attached to the nouns. ' $F$ ' in F1 means female and ' $M$ ' in M1 means male

Table 1 shows the specific values for the degrees of reduction among individual speakers when the suffix [-nin] is attached to the nouns in spontaneous speech. The speakers, F5, M2, M4, and M5 showed the significant differences when using the significance level of 0.001. The speakers, F4, M1, and M3 displayed the significant differences when using the significance level of 0.01 . The speakers F2 and F3 did not have the difference of significance. In Table 1, ' $F$ ' in F2 means female and ' $\mathrm{M}$ ' in $\mathrm{M} 1$ means male. For the degree of reduction on nouns, males tended to have clearer differences among speakers.
Table 1. Statistical summary for individual speakers predicting the degree of reduction when the Korean suffix [-nin] is attached to the nouns

\begin{tabular}{c|c|c|c}
\hline & $\beta$ & $t$-value & $p$-value \\
\hline (Intercept) & 0.389 & 14.156 & $<0.001$ \\
\hline F2 & -0.05 & -1.364 & 0.17 \\
\hline F3 & -0.039 & -1.061 & 0.28 \\
\hline F4 & -0.108 & -2.914 & $<0.01$ \\
\hline F5 & -0.164 & -4.303 & $<0.001$ \\
\hline M1 & -0.103 & -3.094 & $<0.01$ \\
\hline M2 & -0.171 & -4.854 & $<0.001$ \\
\hline M3 & -0.101 & -3.077 & $<0.01$ \\
\hline M4 & -0.182 & -4.676 & $<0.001$ \\
\hline M5 & -0.165 & -4.120 & $<0.001$ \\
\hline & & \multicolumn{2}{|c}{}
\end{tabular}

Figure 4 shows the degrees of reduction for individual speakers when the suffix [-nin] is attached to the verbs. The dots which are correspondent to the curves in the case of verbs seem to be more dispersed over each area than those of nouns. Clearly, each speaker shows a different curve for the degree of reduction. The categorical distinction predicting the difference of the full and reduced form appears for some speakers (e.g., F1, F2, F3, M1, and M4). Other speakers display the gradient curves for the different degrees of reduction. For example, the speakers F5 and M2 show gradient curves indicating that there is a difference between full and reduced form, though their slopes are a little similar.

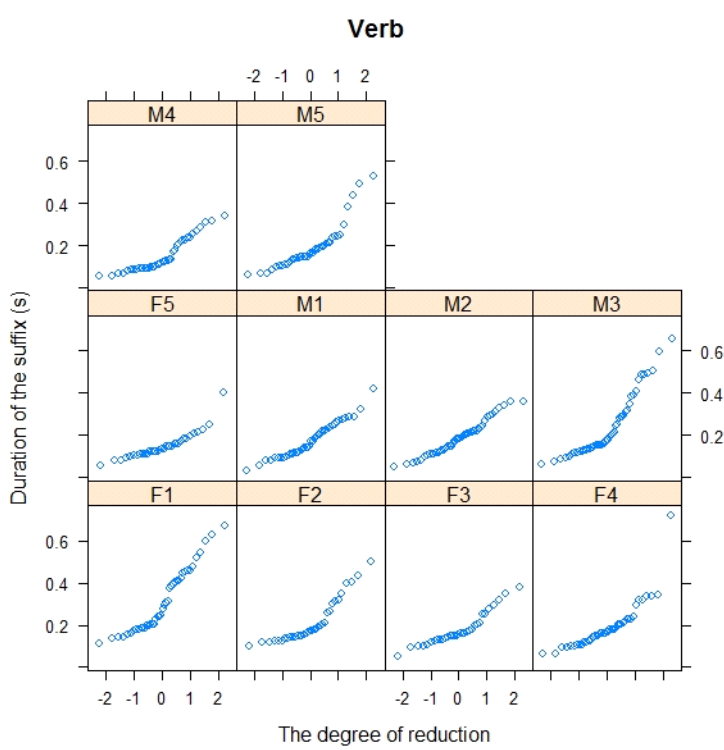

Figure 4. The degree of reduction for each speaker when the Korean suffix [-nin] is attached to the verbs

The statistical summary of the Table 2 supports the individual differences shown in Figure 4. The model in the Table 2 showed that speakers varied in their sensitivity to the degree of reduction. All speakers revealed their differences in the significance level of 0.001 . When the suffix [-nin] is attached to the verbs, the patterns for the degrees of reduction among speakers are clearly different. 
Table 2. Statistical summary for individual speakers predicting the degree of reduction when the Korean suffix [-nin] is attached to the verbs

\begin{tabular}{c|c|c|c}
\hline & $\beta$ & $t$-value & $p$-value \\
\hline (Intercept) & 0.312 & 19.218 & $<0.001$ \\
\hline F2 & -0.101 & -4.213 & $<0.001$ \\
\hline F3 & -0.135 & -5.532 & $<0.001$ \\
\hline F4 & -0.122 & -5.412 & $<0.001$ \\
\hline F5 & -0.164 & -6.824 & $<0.001$ \\
\hline M1 & -0.137 & -6.043 & $<0.001$ \\
\hline M2 & -0.127 & -5.724 & $<0.001$ \\
\hline M3 & -0.074 & -3.38 & $<0.001$ \\
\hline M4 & -0.163 & -7.079 & $<0.001$ \\
\hline M5 & -0.124 & -5.326 & $<0.001$ \\
\hline & & &
\end{tabular}

Figure 5 shows the degrees of reduction for individual speakers when the suffix [-nin] is attached to the pronouns. In the Figure 5 , the curves for speakers seem to be irregular. The speakers, F1, F2, F3, and M1 showed more irregular than other patterns, and the dots of each area for these speakers tended to be dispersed. But for other speakers, the dots correspondent to each curve tended to be condensed, showing that there is the gradient curve for each speaker's pronunciation. Overall, the patterns between full and reduced forms for pronouns are less varied among individual speakers, compared to those shown in nouns and verbs.

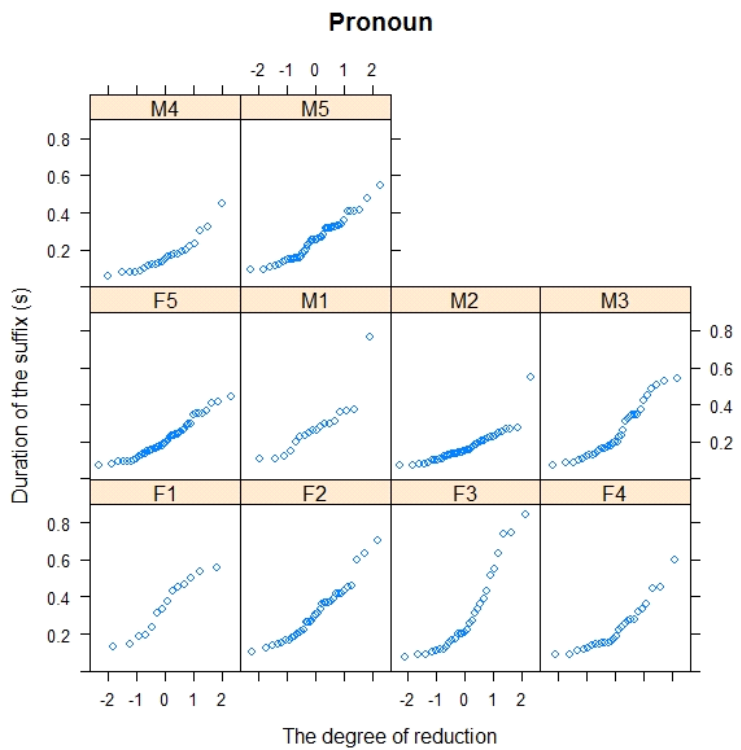

Figure 5. The degree of reduction for each speaker when the Korean suffix [-nin] is attached to the pronouns

Table 3 provides the $p$-values for the degrees of reduction produced by individual speakers. The speakers M2 and M4 were statistically differed with $\mathrm{F} 1$ by the significant level of 0.001 . The speakers M3 and M5 showed that there was a difference in the 0.05 significant level. On a basis of the $p$-values in Table 3 , the differences of individual speakers tended to appear for males, rather than those of females. That is, the speakers F4 and F5 were differed by the significant level of 0.01 , and there were no significant effects for other females.
Table 3. Statistical summary for individual speakers predicting the degree of reduction when the Korean suffix [-nin] is attached to the pronouns

\begin{tabular}{c|c|c|c}
\hline & $\beta$ & $t$-value & $p$-value \\
\hline (Intercept) & 0.345 & 9.892 & $<0.001$ \\
\hline F2 & -0.033 & -0.818 & 0.41 \\
\hline F3 & -0.044 & -1.054 & 0.29 \\
\hline F4 & -0.115 & -2.665 & $<0.01$ \\
\hline F5 & -0.132 & -3.318 & $<0.01$ \\
\hline M1 & -0.069 & -1.492 & 0.13 \\
\hline M2 & -0.175 & -4.384 & $<0.001$ \\
\hline M3 & -0.095 & -2.308 & $<0.05$ \\
\hline M4 & -0.179 & -4.045 & $<0.001$ \\
\hline M5 & -0.091 & -2.283 & $<0.05$
\end{tabular}

3.3. The degree of reduction based on the number of syllables

The length of a root in spontaneous speech may play a role to have an influence on the degrees of suffix reduction when the Korean suffix [-nin] is attached. The present study examines the number of syllables correspondent to the roots in order to assess the reduction of the suffix [-nin]. For the overall data, the duration of the suffix [-nin] showed the significant difference based on the syllable number of each root $(\beta=0.011, t=2.786$, $p<.01$ ). Specifically, two-syllable roots, three-syllable roots, and four-syllable roots were examined to find out their effect for the reduction degree of the suffix [-nin].

Figure 6 shows the degrees of reduction for individual speakers when the suffix [-nin] is attached to the two-syllable roots. The most of responses on the duration of the suffix [-nin] were displayed as the gradient or continuous curves, though there were different slopes among speakers. For some speakers, there were categorical distinctions in the middle of curves (e.g., M3, M4). These speakers seem to show the distinction between the full and reduced forms.

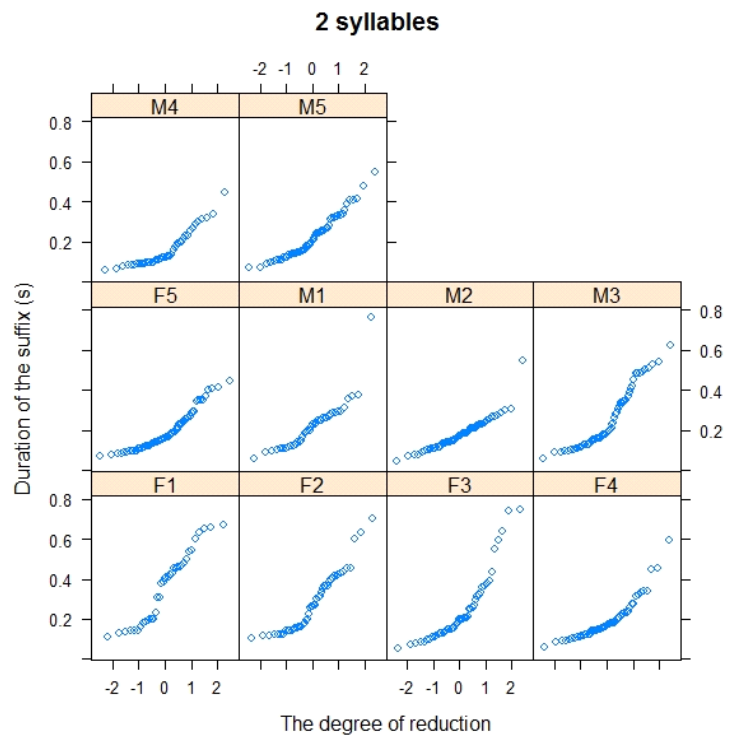

Figure 6. The degree of reduction for each speaker when the Korean suffix [-nin] is attached to the two-syllable roots

Table 4 shows the specific values for individual speakers in the degree of reduction when the suffix [-nin] is attached to the two-syllable roots. In the model of Table 4, the speaker F2 
were the distinctive effect of the significant level of 0.01 . Other speakers exhibited the strong differences of the significant level of 0.001 in the degree of reduction when pronouncing the suffix [-nin]. Considering these values, the two-syllable roots exhibit the clear effect to differentiate the degrees of reduction among speakers.

Table 4. Statistical summary for individual speakers predicting the degree of reduction when the Korean suffix [-nin] is attached to the two-syllable roots

\begin{tabular}{c|c|c|c}
\hline & $\beta$ & $t$-value & $p$-value \\
\hline (Intercept) & 0.361 & 17.836 & $<0.001$ \\
\hline F2 & -0.079 & 0.026 & $<0.01$ \\
\hline F3 & -0.119 & -4.463 & $<0.001$ \\
\hline F4 & -0.116 & -6.364 & $<0.001$ \\
\hline F5 & -0.171 & -6.899 & $<0.001$ \\
\hline M1 & -0.139 & -4.953 & $<0.001$ \\
\hline M2 & -0.181 & -7.041 & $<0.001$ \\
\hline M3 & -0.111 & -4.372 & $<0.001$ \\
\hline M4 & -0.201 & -7.347 & $<0.001$ \\
\hline M5 & -0.138 & -5.395 & $<0.001$ \\
\hline & & &
\end{tabular}

Figure 7 shows individual reduction degrees when the suffix [-nin] is attached to the three-syllable roots. In Figure 7, the curve for each speaker was not steep, though the speaker F3 showed some outliers on its area. The curves of speakers, F5, M1, M2, M3, M4, and M5 were gradient, indicating that there were no distinctive boundaries between full and reduced forms. The curves of F1, F2, F3, and F4 tended to have more or less irregular patterns.

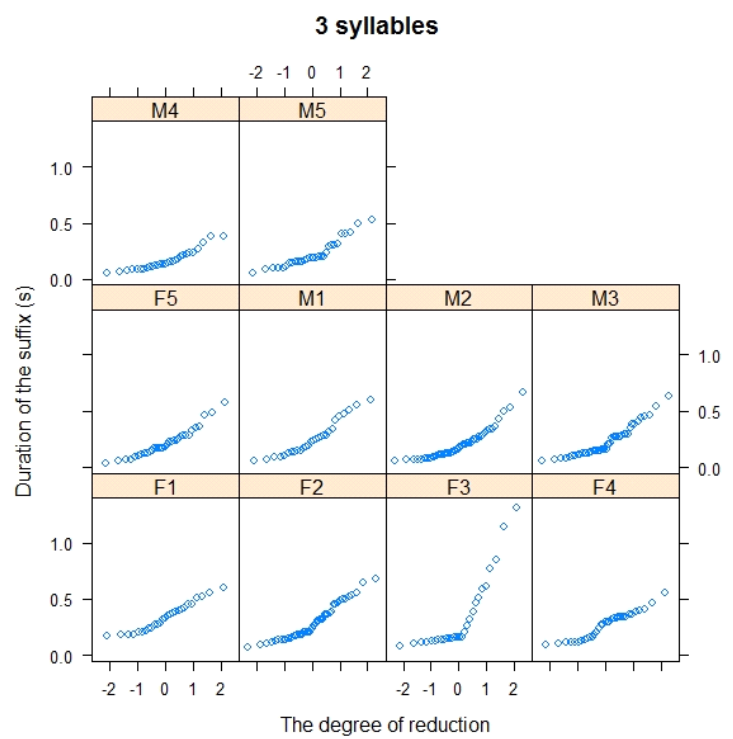

Figure 7. The degree of reduction for each speaker when the Korean suffix [-nin] is attached to the three-syllable roots

Table 5 shows the statistical values of individual speakers for presenting the degree of reduction when the attachment of the suffix [-nin] to the three-syllable root is occurred. In Table 5, the speakers F5, M1, M2, M3, M4, M5 were significant effects on the degrees of reduction. Especially, M2 and M4 had the strong distinctions of the significance level of 0.001 compared to other speakers. The degrees of reduction were significantly different among males. On the other hand, for females, there were no significant differences except the speaker F5. That is, the degree of reduction tended to have more variations for males than for females.

Table 5. Statistical summary for individual speakers predicting the degree of reduction when the Korean suffix [-nin] is attached to the three-syllable roots

\begin{tabular}{c|c|c|c}
\hline & $\beta$ & $t$-value & $p$-value \\
\hline (Intercept) & 0.338 & 11.244 & $<0.001$ \\
\hline F2 & -0.048 & -1.293 & 0.19 \\
\hline F3 & 0.005 & 0.129 & 0.89 \\
\hline F4 & -0.073 & -1.801 & 0.07 \\
\hline F5 & -0.121 & -2.987 & $<0.01$ \\
\hline M1 & -0.083 & -1.974 & $<0.05$ \\
\hline M2 & -0.134 & -3.601 & $<0.001$ \\
\hline M3 & -0.111 & -2.943 & $<0.01$ \\
\hline M4 & -0.172 & -4.140 & $<0.001$ \\
\hline M5 & -0.114 & -2.790 & $<0.01$
\end{tabular}

Figure 8 exhibits the reduction degrees for individual speakers when the suffix [-nin] is attached to the four-syllable roots. In this figure, the female speakers did not show the curves with dots which are condensed. And they tended to have some space between dots on the curve. On the other hand, the reduction degrees were a lot more continuous for males than for females. For most of males, the curves on their areas seem to have the absence of clear boundaries, indicating that there is a continuum between both ends of the full and reduced form.

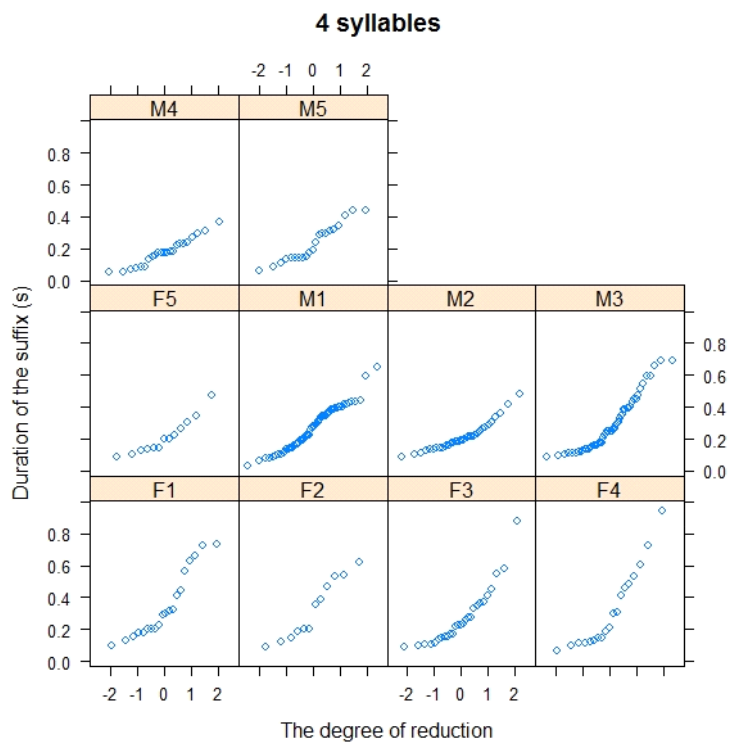

Figure 8. The degree of reduction for each speaker when the Korean suffix [-nin] is attached to the four-syllable roots

Table 6 shows the statistical values for individual speakers predicting the degree of reduction when the suffix [-nin] is attached to the four-syllable roots. For the four-syllable roots, the degree of reduction for the suffix [-nin] had the strongest distinction for the speaker M4 as the significance level of 0.001 . When distinguishing the degrees of reduction among individual 
speakers in Table 6, males had more significant effects than females. The female speakers were less likely to have individual differences than the male speakers in terms of the degrees of reduction.

Table 6. Statistical summary for individual speakers predicting the degree of reduction when the Korean suffix [-nin] is attached to the four-syllable roots

\begin{tabular}{c|c|c|c}
\hline & $\beta$ & $t$-value & $p$-value \\
\hline (Intercept) & 0.348 & 10.085 & $<0.001$ \\
\hline F2 & -0.027 & -0.482 & 0.62 \\
\hline F3 & -0.072 & -1.589 & 0.11 \\
\hline F4 & -0.028 & -0.578 & 0.56 \\
\hline F5 & -0.137 & -2.491 & $<0.05$ \\
\hline M1 & -0.078 & -1.97 & $<0.05$ \\
\hline M2 & -0.136 & -3.161 & $<0.01$ \\
\hline M3 & -0.059 & -1.457 & 0.14 \\
\hline M4 & -0.169 & -3.597 & $<0.001$ \\
\hline M5 & -0.117 & -2.443 & $<0.05$ \\
\hline
\end{tabular}

\section{Discussion}

4.1. The degree of reduction based on parts of speech and syllables

For the present study, the parts of speech include verbs, nouns, and pronouns. These elements give some effects when the suffix [-nin] is attached to the root. The reduction patterns for the verbs are varied when the suffixes are attached to the roots. The production patterns of the suffixes appear as the variants of the full and reduced forms, showing various durations of the suffixes. In this paper, the overall relation of the full and reduced forms was marked as gradient or continuous curves. Some speakers' pronunciations tended to show categorical boundaries between full and reduced forms. This categorical tendency was more distinctive for verbs than nouns and pronouns. But for verbs, there were gradient curves between the full and reduced forms. For nouns, there was prominent for gradient curves than for categorical distinctions. The gradient curves on the degrees of reduction indicate that the coda duration of the suffix [-nin] between the full and reduced form increasingly shortens. The degrees of reduction for pronouns were more dispersed than those of verbs and nouns, showing dots with wider intervals of time. For the present study, the parts of speech on the degree of reduction of the suffix [-nin] were distinctive, showing the different degrees of reduction. This means that the degrees of reduction on suffix coda durations tended to be flexible when they produce with the qualities of various roots.

When the suffix [-nin] is attached to the root in spontaneous speech, the occurrence of suffix reduction has an effect on the length of a root. The present study observed that when two-syllable roots, the degree of suffix reduction was more distinctive than for three- and four-syllable roots. For two- syllable roots, there were categorical boundaries in the middle of reduction curves for some speakers when presenting the relation of the full and reduced forms. The other speakers exhibited the gradient or continuous curves for the degree of reduction. Their reduction curves were more condensed than those of three- and four-syllable roots. For three-syllable roots, there were no categorical distinctions on the curves. Their reduction curves were gradient for the most of speakers. The most of curves for the four-syllable roots were irregular, though there were some gradient curves on the degree of reduction. For the present study, the degree of reduction for the length of a root with two syllables was clearer than that for the length of roots with longer syllables. When the length of a root was shorter, the suffix reduction tended to clearly occur.

4.2. The degree of reduction based on the pronunciations of individual speakers

The individual speakers of the present study showed some variations on the degree of reduction under these two conditions such as the parts of speech and the number of syllables. Considering the parts of speech, when the suffix [-nin] was attached to verbs, the individual speakers exhibited clearly different curves on the degree of reduction. These differences among individual speakers can be marked as the significance level of 0.001 . For nouns, the significance level played a different role for the speakers of the present study. In this case, the four speakers were clearly distinctive in the significance level of 0.001 . The three speakers had an important difference in the significance level of 0.01 . The degree of reduction for the other two speakers was not significantly different. The significance levels for pronouns among individual speakers were a lot more different than those of verbs and nouns. For pronouns, the reduction degrees of eight speakers were marked as the significance level of 0.001 , that of 0.01 , and that of 0.05 . The other two speakers were not significantly different. Among individual differences for the verbs, nouns, and pronouns, the speakers, M2 and M4, showed their strong sensitivity on the degree of reduction in the significance level of 0.001. Finally, what is interesting here for nouns and pronouns is that male speakers were clearer differences than female speakers. For the future study, the gender differences on the degree of reduction need to have an in-depth study.

When the suffix [-nin] was attached to the two-syllable root, the reduction degree clearly showed the differences among individual speakers. The distinctive effect among individual speakers appeared as the significant level of 0.001 , except for one speaker (e.g., $p<.01$ ). For two speakers (e.g., M3 and M4), there were categorical distinctions in the middle of the curves, indicating that these speakers distinguished the relation of the full and reduced forms. For other speakers, there were different slopes among individual speakers, maintaining the gradient or continuous curves. The individual differences on the reduction degrees related to the three-syllable roots were less distinctive than those related to the two-syllable roots. The only two speakers showed the significant level of 0.001 . The degree of the significant level on reduction were varied as the level of 0.01 and 0.05 among individual speakers. Three speakers related to the three-syllable roots did not show any individual differences. The individual differences on the four-syllable roots were less distinctive than the two- and three-syllable roots. The speaker M4 were clearly distinctive as the significant level of 0.001 . The four speakers were distinguished as the variations of significant level of 0.01 and 0.05 . The other four speakers did have no differences. Regarding the degree of reduction on the syllable number of each root, individual differences were more sensitive to the root with shorter length than longer length. 


\section{Conclusion}

The present study examined the degree of reduction of Korean suffix [-nin] for individual speakers when it is attached to the root in spontaneous Seoul Korean speech. The patterns of reduction were assessed as the duration of the suffix [-nin], showing the continuum between the full and reduced forms. There are three findings from the results of the present study. First, the durations of the full and reduced forms significantly differed. The overall duration range of the full forms was between 0.0 and $1.0 \mathrm{sec}$, and that of the reduced forms was between 0.0 and $0.5 \mathrm{sec}$. Second, considering the parts of speech, the degrees of reduction for individual speakers were more significantly differed when the suffix [-nin] is attached to verbs than nouns and pronouns. The curves when producing verbs with the suffix attachment were gradient between the full and reduced forms, though the slopes of the curves were different for individual speakers. The production of individual speakers was more dispersed for pronouns than verbs and nouns. Third, the length of a root plays a critical role when the suffix attached to it. The reduction patterns among individual speakers were more varied for two-syllabic roots than for threeand four-syllabic roots. In sum, the results showed that the most distinct individual differences tended to occur when the roots are verbs, and when two-syllabic words.

\section{References}

Bates, D., Machler, M., Bolker, B. M., \& Walker, S. C. (2015). Fitting linear mixed-effects models using lme4. Journal of Statistical Software, 67(1), 1-48.

Bayley, R. (1997). Variation in Tejano English: Evidence for variable lexical phonology. In: C. Bernstein, T. Nunnaly, \& R. Sabino (eds.), Language variety in the south revisited. Tuscaloosa, AL: University of Alabama Press.

Bock, J. (1995). Sentence production: From mind to mouth. In J. Miller \& P. Eimas (Eds.), Handbook of perception and cognition, Speech, language, and communication (Vol. 11, pp. 181-216). London, UK: Academic Press.

Bybee, J. (2001). Phonology and language use. Cambridge, UK: Cambridge University Press.

Coetzee, A. W., \& Pater, J. (2011). The place of variation in phonological theory. In: J. Goldsmith, J. Riggle, \& A. C. L. Yu (eds.), The handbook of phonological theory (2nd ed.). Oxford, UK: Blackwell.

Cooper, W. E., \& Paccia-Cooper, J. (1980). Syntax \& speech. Cambridge, MA: Harvard University Press.

Ernestus, M. T. C. (2000). Voice assimilation and segment reduction in casual Dutch: A corpus-based study of the phonologyphonetics interface. Utrecht, Netherland: LOT.

Guy, G. R. (1991). Explanation in variable phonology: an exponential model of morphological constraints. Language Variation and Change, 3(1), 1-22.

Hong, S., \& Park, S. (2016). Korean reduced words from the perspective of information theory. Linguistic Research, 33(2), 349-374.

Johnson, K. (2004, January). Massive reduction in conversation American English. Spontaneous speech: data and analysis.
Proceedings of the 1st session of the 10th International Symposium (pp. 29-54). Tokyo, Japan.

Jurafsky, D., Bell, A., Gregory, M., \& Raymond, W. (2001). Probabilistic relations between words: Evidence from reduction in lexical production. In J. Bybee \& P. Hopper (Eds.), Frequency and the emergence of linguistic structure (pp. 229-254). Amsterdam, Netherland: John Benjanins.

Kim, J. S. (2016). Affixation effects on word-final coda deletion in spontaneous Seoul Korean speech. Phonetics and Speech Sciences, 8(4), 9-14.

Levelt, W. J. M. (1989). Speaking: From intention to articulation. Cambridge, MA: MIT Press.

Lohmann, A., \& Conwell, E. (2020). Phonetic effects of grammatical category: How category-specific prosodic phrasing and lexical frequency impact the duration of nouns and verbs. Journal of Phonetics, 78, 1-22.

Martin, A. D., Quinn, K. M., \& Park, J. H. (2011). MCMC pack: Markov Chain Monte Carlo in R. Journal of Statistical Software, 42(9), 1-21.

Pluymaekers, M. (2007). Affix reduction in spoken Dutch: Probabilistic effects in production and perception (Ph.D. Dissertation). Radboud University, Nijmegen, Netherland.

Santa Ana, O. (1992). Phonetic simplication processes in the English of the Barrio: a cross-generational sociolinguistic study of the Chicanos of Los Angeles (Ph.D. Dissertation). University of Pennsylvania, Philadelphia, PA.

Scarborouogh, R. A. (2003, January). Degree of coarticulation and lexical confusability. Proceedings of the 29th Meeting of the Berkeley Linguistics Society. Berkeley, CA.

Shields, L. W., \& Balota, D. A. (1991). Repetition and associative context effects in speech production. Language and Speech, 34(1), 47-55.

Umeda, N. (1977). Consonant duration in American English. Journal of the Acoustical Society of America, 61(3), 846-858.

Van Son, R., \& Pols, L. (2003, September). Information structure and efficiency in speech production. Proceedings of Eurospeech 2003. Geneva, Switzerland.

Wright, R. A. (1997). Lexical competition and reduction in speech: A preliminary report. Research on Spoken Language Processing. Progress Report No. 21, Indiana University, 471-484.

Yun, W., Yoon, K., Park, S., Lee, J., Cho, S., Kang, D., Byun, K., Hahn, H., \& Kim, J. (2015). The Korean corpus of spontaneous speech. Phonetics and Speech Sciences, 7(2), 103-109.

- Jungsun Kim, Corresponding author Associate Professor, Graduate School of Education Yeungnam University 280 Daehak-ro, Gyeongsan 38541, Korea Tel: +82-53-810-7825 Email: jngsnkim@gmail.com Fields of interest: Phonetics, Phonology, Psycholinguistics 